\title{
Modelling 3D dan Animating Karakter pada Game Edukasi "World War D" Berbasis Android
}

\author{
Mifta Fadya ${ }^{1}$, Irma Permata Sari ${ }^{2}$ \\ Teknik Informatika dan Komputer \\ Politeknik Negeri Jakarta \\ mitaafd@gmail.com ${ }^{1}, \underline{\text { irma.permatasari@tik.pnj.ac.id }}{ }^{2}$
}

Diterima: 20 Oktober 2018. Disetujui Oktober 2018. Dipublikasikan November 2018

\begin{abstract}
Abstrak - Penyakit difteri merupakan sebuah penyakit yang disebabkan oleh bakteri Corynebacterium diphtheriae. Penyakit ini menyerang sistem pernapasan bagian atas dan umumnya pada anak usia 0 - 10 tahun. Penyakit menular ini sebenarnya mampu dicegah dengan imunisasi, namun penurunan angka kesadaran untuk melakukan imunisasi ini terjadi karena kurangnya pendidikan dan pemahaman akan hal tersebut. Serta rendahnya minat yang dimiliki oleh anak-anak untuk melakukan imunisasi. Saat ini game merupakan sarana yang tepat untuk dijadikan sebagai media alternatif pembelajaran serta pengenalan suatu hal kepada anak. Karena selain menghibur, anak-anak mendapatkan eduk asi yang terkandung di dalam game tersebut. Game yang dibuat berjudul "World War D" ini merupak an game 2.5D memiliki genre eduk asi advanture. Pada pembuatan game ini menggunakan teknik pemodelan primitive modeling serta menggunakan fitur mirror modifier, subvision surface, dan lain-lain. Dalam pembuatan animasi karakter menggunakan 7 dari 12 prinsip dasar animasi. Pembuatan model karakter 3D dan animasi karakter dilakukan dengan menggunak an perangkat lunak Blender. Hasil pengujian alfa dari pembuatan model karakter 3D dan animasi karakter 3D ini sudah cocok dengan game secara keseluruhan. Dan hasil pada pengujian beta me mperoleh $29,93 \%$ pada jawaban "sangat setuju" dan 56,01\% untuk jawaban "setuju" pada setiap poin pertanyaan.
\end{abstract}

Kata kunci: Game Edukasi, Difteri, 3d, Modeling, Blender

\section{PENDAHULUAN}

Penyakit difteri merupakan sebuah penyakit Re-emerging Disease yang disebabkan oleh bakteri Corynebacterium diphtheriae yang menyerang sistem pernapasan bagian atas. Penyakit ini umu mnya menyerang anak-anak usia $1-10$ tahun [1]. Penyakit ini menyerang selaput lendir atau radang konjungtiva atau vagina, jantung, ginjal, sistem saraf sehingga berakibat susah menelan, kele mahan otot, sesak nafas, bahkan gagal jantung yang dapat berakibat kematian yang mendadak [2].

Pada tahun 2016, World Health Organization (WHO) mencatat sebanyak 7.097 kasus difteri yang terjadi di seluruh dunia[3]. Berdasarkan hasil laporan yang ada, Indonesia mendapati sebanyak 415 kasus pada tahun 2016 dengan jumlah kasus meninggal sebanyak 24 kasus. Dari seluruh kasus difteri, 51\% diantaranya tidak memiliki riwayat imunisasi. Pada kasus difteri ini, 59\% terjadi pada kelo mpok umur 1-4 tahun dan 5-9 tahun[1].Wabah penyakit difteri sudah ada sejak dulu, namun muncul kembali karena kesadaran masyarakat akan mengantisipasi penyakit tersebut menurun. Imunisasi Dasar Lengkap (IDL) kepada anak-anak belum pernah mencapai angka $100 \%$. Hal in i disebabkan oleh berbagai faktor, salah satu faktor tersebut ialah pendidikan tentang pemahaman pentingnya imunisasi yang diberikan kepada masyarakat belum maksimal. Selain itu, sosialisasi akan pentingnya imunisasi tidakhanya menjadi tugas Kementerian Kesehatan, namun menjadi tanggung jawab seluruh masyarakat Indonesia[4]

Mengenalkan pendidikan tentang penyakit difteri kepada anak-anak merupakan salah satu solusi untuk mengurangi penyebaran wabah penyakit tersebut. Menurut Jong et al., media pendidikan yang dapat dijadikan alternatif sebagai media pembelajaran serta pengenalan suatu hal kepada anak dapat berupa game edukasi. Game edukasi merupakan game yang tidak hanya bersifat menghibur, namun didalamnya memiliki unsur pengetahuan yang disampaikan kepada penggunanya[5].

Maka dari itu dibuat mobile game berbas is 2.5 dimensi dengan teknologi platform Android berjudul 'World War D' dengan tema lingkungan bertujuan untuk melawan penyakit difteri yang dikemas dalam bentuk permainan berjenis advanture yang simple dan ringan.Mobile game 2.5 dimensi berjudul 'World War D' ini memiliki 
karakter dan latar ling kungan yang dibuat dalam bentuk 3 dimensi. Tampilan animasi citra 3 dimensi dalam sebuah permainan menghasilkan kualitas yang jauh lebih baik, serta memiliki grafik pergerakan dan style yang lebih bagus daripada animasi citra 2 dimensi [6] dan dalam penggunaan objek 3D dapat meningkatkan performa yang lebih baik daripada mereka yang hanya menggunakan 2D [7]. Untuk membagun game 'World War D' dengan visualisasi yang menarik dan atraktif dibutuhkan seorang modeler dan animator 3 dimensi yang berperan membuat model 3 dimensi dan animasi karakter utama pada permainan tersebut. Dari permasalahan yang telah disebutkan, maka dibuat judul skripsi "Modelling 3D dan Animating Karakter Pada Game Edukasi 'World War D' Berbasis Android" agar dapat membantu proses pembutan game edukasi-advanture 'World War D' ters ebut.

\section{LANDASAN TEORI}

\section{A. Difteri}

Difteri adalah sebuah penyakit menular akibat infeksi yang disebabkan oleh bakteri Corynebacterium diphtheriae, yang menyerang bagian selaput lendir (muсus) pada tenggorokan dan hidung. Dalam beberapa kondisi penyakit difteri juga dapat menyerang kulit. Difteri menjangkit seluruh kalangan masyarakat dari selaga usia, namun anak-anak yang tidak mendapatkan imunisasi lebih rentan terkena difteri. Di daerah yang memiliki iklim cenderung tropis, difteri lebih mudah menyebar [8]. Corynebacterium diphtheriae diklasifikasikan menjadi biotipe (mitis, intermedius, dan gravis) menurut morfologi koloni, serta menjadi lisotip berdasarkan sensitivitas corynebacteriophage. Corynebacterium diphtheriae disebarkan oleh tetesan, sekresi, atau kontak langsung. Infeksi menyebar hanya di antara manusia, meskipun strain toksigenik telah diisolasi dari kuda.Wabah penyakit dengan skala besar dapat terjadi pada populasi di daerah yang memiliki program imun is asi yang tidak dipelihara [9].

\section{B. Game}

Teori yang dikemukakan oleh Katie Salen dan Eric Zimmerman (dalam Ekawati, 2015) game atau permainan merupakan sebuah sistem di mana pemain terlibat dalam konflik buatan yang ditentukan oleh aturan yang menghasilkan hasil yang terukur. Sedangkan menurut David Parlett, game adalah sesuatu yang memiliki akh ir dan cara pencapaiannya. Dalam game terdapat tujuan, hasil dan serangkaian peraturan untuk mencapai keduanya. Sehingga game merupakan sarana yang menangani hubungan input/output, yang dikemas dalam sebuah sistem dimana pemain terlibat dalam konflik buatan yang sudah ditentukan oleh aturan memilih strategi yang dibangun untuk memaksimalkan sebuah hasil menuju suatu tujuan tertentu[10].

\section{Mobile Games}

Mobile games adalah game yang dirancang untuk perangkat seluler, seperti smartphones dan tablet. Mobile game memiliki ragam jenis, mulai dari yang dasar seperti game Snake pada ponsel Nokia lama hingga game realitas canggih (3D dan augmented reality). Saat ini mobile phones terutama smartphones memiliki berbagai fitur konektivitas termasuk inframerah, Bluetooth, Wi-Fi, dan 3G/4G. Teknologi tersebut memfasilitasi game multiplayer nirkabel dengan dua atau lebih pemain dimanapun berada [11].

\section{Game Edukasi}

Game edukasi adalah sebuah permainan yang memiliki konten pendidikan. Game berjenis edukasi bertujuan untuk memancing minat belajar anak terhadap suatu pelajaran sehingga akan lebih mudah memahami suatu materi[12]. Sedangkan game edukasi menurut Edward (2009) dalam (Anggraini, et al., 2016) game merupakan sebuah tools yang efektif untuk mengajar karena mengandung prinsip-prinsip pembelajaran dan teknik instruksional yang efektif digunakan dalam penguatan pada level-level yang sulit.

\section{E. Game Adventure}

Game ini merupakan jenis game yang menekankan pada penyelesaian jalan cerita. Game ini tidak seperti aksi yang membutuhkan kecepatan refleks. Game ini hanya membutuhkan ketajaman analisis dan kekuatan hafalan, karena di sisi pe main akan diminta memecahkan teka-teki ataupun menyimpulkan rangkaian peristiwa dari percakapan karakter hingga ke penggunaan benda yang ada dalam permainan[12].

\section{F. 3 Dimensi}

3 Dimensi atau 3D mempunyai bentuk, volume, dan ruang. Sehingga objek ini memiliki koordinat X, Y, dan Z.Pada umumnya objek 3D memiliki sub objek berupa elemen-elemen pembentuk objek tersebut, yang berupa Vertex, Edge, dan Face. Vertex merupakan titik yang terletak pada koordinat X, Y, Z. Penggabungan dua Vertex akan menjadi Edge. Tiga Vertex dan Edge yang terbentuk dalam bidang permukaan berupa kurva tutup akan menghasilkan Face. Kumpulan dari Vertex, Edge, dan Face akan menjadi sebuah objek utuh yang disebut dengan Mesh[13].

\section{G. 3DModeling}

$3 D$ modeling atau pemodelan 3 Dimensi (3D) sebuah proses pembuatan representasi 3D dari setiap latar atau objek dengan memanipulasi polygon, edges, dan vertices dalam ruang simulasi 3D. Pemodelan 3D dapat dicapai secara manual dengan perangkat 3D khusus yang memungkinkan 
seniman menciptakan dengan memindai objek dunia nyata menjadi serangkaian titik-titik data yang dapat digunakan untuk merepresentasikan objek secara digital[14].

\section{H. Rigging}

Rigging adalah proses menambahkan tulang ke karakter atau mendefinisikan gerakan benda mekanis. Ini adalah pusat proses animasi karena akan menunjukkan bagaimana karakter muncul ketika berubah bentuk menjadi pose yang berbeda. Proses tali-temali melibatkan menciptakan kerangka, menambahkan kulit ke bagian rangka tubuh dan kemudian menempelkan bagian-bagian yang berbeda bersama-sama [15].

\section{Animasi}

Animasi adalah proses membawa atau membuat objek virtual ke dalam kehidupan nyata, untuk melakukan hal tersebut, seorang animator memerlukan kumpulan kontrol dan manipulator, yang akan memungkin kan untuk mengontrol setiap bagian karakter dan animasi[16]. Animasi berasal dari bahasa inggris yaitu animate yang artinya menghidupkan, memberi jiwa dan mengerakan benda mati. Animasi merupakan proses membuat objek yang asalnya objek mati, kemudian disusun dalam posisi yang berbeda seolah menjadi hidup. Di dalam animasi ada dua objek penting, yaitu objek atau gambar dan alur gerak. Animasi secara umum dapat dikatakan sebagai suatu sequence gambar yang ditampilkan pada tenggang waktu (timeline) tertentu sehingga tercipta sebuah ilusi gambar bergerak [17].

\section{METODOLOGI}

Metode yang digunakan dalam pembuatan produk multimedia ini adalah metode Luther, di mana metode ini meliputi tahap-tahap sebagai berikut.

1. Konsep, merupakan tahap awal dalam membuat produk multimedia, yaitu berupa menentukan spesifikasi dari bentuk akhir karakter 3 dimensi (3D) yang akan dibuat berdasarkan ide, jenis aplikasi, serta sasaran penggunaan aplikasi. Dalam pembuatan game "World War D" ini dibutuhkan perencanaan yang matang agar tersampaikan pesan edukasi yang ingin diberikan serta mampu memberikan pengalaman yang menarik kepada pe mainnya. Perencanaan yang dilakukan meliputi perancangan awal berupa karakter 2 dimensi (2D) hingga karakter 3 dimensi (3D). Berikut adalah penjelasan spesifik permainan yaitu meliputi: konsep permainan, cara kerja permainan, dan spesifikasi alat yang akan digunakan.

a. Konsep Permainan, dalam permainan ini memiliki konsep single player dengan platform berbasis Android yang memiliki tema lingkungan yang bersifat edukasiadventure.

b. Cara kerja Permainan, pada game "World War D" dapat digambarkan dengan Finite State Machine (FSM) yang digambarkan sebagai berikut.

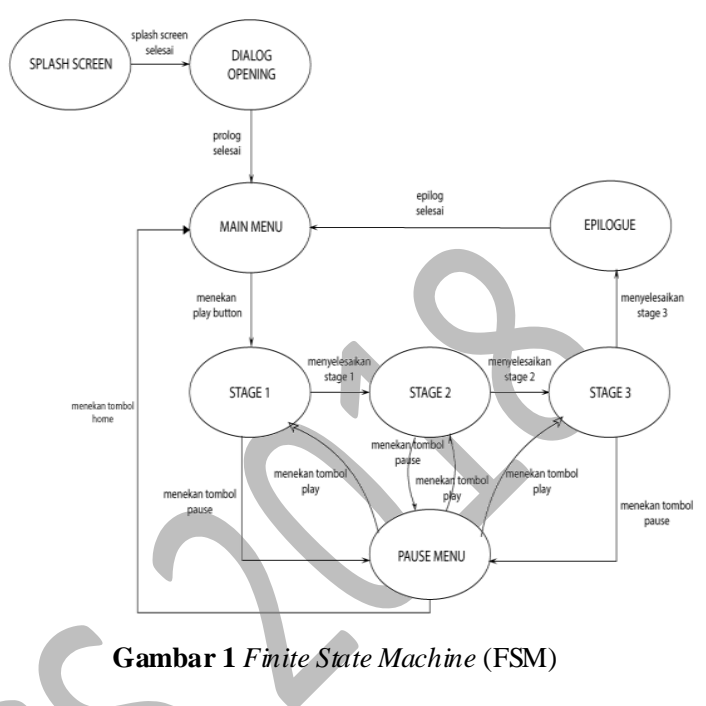

c. Spesifikasi Alat, dalam membuat permainan ini menggunakan spesifikasi alat laptop dan smartphone Android serta perangkat lunak Blender versi $2.79 \mathrm{~b}$.

2. Desain, pada tahap ini merupakan tahap pembuatan desain karakter secara rinci dalam bentuk 2 dimensi (2D) yang kemudian akan digunakan sebagai acuan pembuatan karakter 3D dengan menggunakan perangkat lunak Blender. Serta pembuatan storyboard yang dibuat secara terperinci. Dalam proses desain tersebut dijelaskan sebagai berikut.

a. Desain Karakter, karakter utama dalam mobile game ini bernama Batraz. Batraz diambil dari kata bagatur dalam Bahasa Turki yang berarti pahlawan; prajurit; atau pemberani. Batraz adalah seorang anak kecil yang tinggal di sebuah kota kecil yang sedang mengalami bahaya penularan penyakit mematikan yaitu difteri. Batraz memiliki sifat yang optimis, kuat dan pemberani seperti namanya.

b. Storyboard, pembuatan storyboard digunakan untuk mencegah penyimpangan alur cerita yang telah dirancang.

3. Pengumpulan Materi (Material Collecting), pada tahap ini dilakukan pengumpulan assetaset pendukung dari pembuatan karakter 3D dan user interface pada aplikasi. Dibawah ini merupakan daftar aset yang termasuk dalam tahap pengumpulan material. 
TABEL 1 DAFTAR ASET

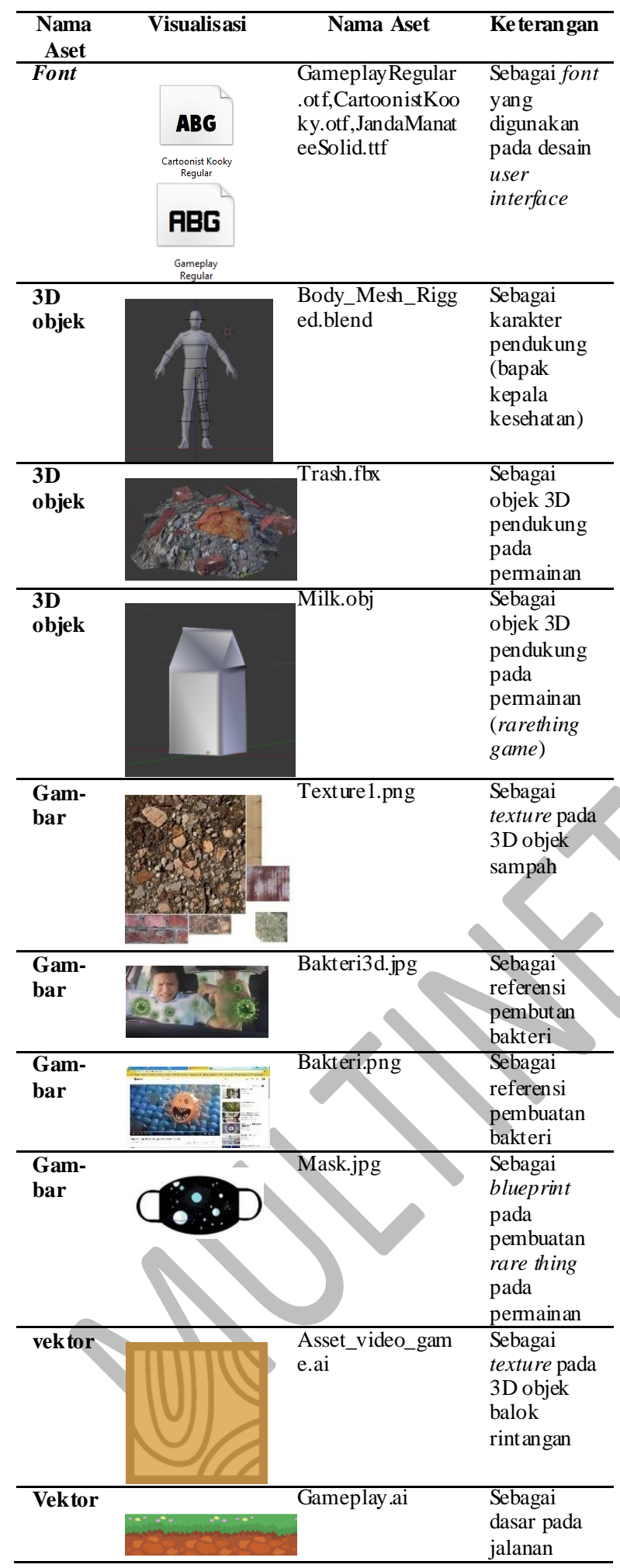

4. Penggabungan (Assembly), tahap pembuatan dan penggabungan dari objek karakter yang dibuat serta pembuatan animasi pergerakan karakter 3D untuk kemudian digabungkan menjadi satu kesatuan karakter 3D yang dapat dieksekusi ke tahap pembangunan aplikasi. a. Modeling, pada proses pembuatan model karakter 3D ini menggunakan perangkat lunak Blender dengan beberapa tahap yang dilalui.Proses pembuatan model 3D memiliki beberapa cara, dalam pembuatan karakter pada permainan mobile phone ini adalah primitive modeling. Teknik ini merupakan teknik yang pembuatan awalnya menggunakan objek yang sudah disediakan oleh perangkat lunak Blender. Pada pembuatan karakter ini menggunakan object cube. Penggunaan object cube ini dilakukan karena cube memiliki bentuk dasar yang mudah dibentuk dan dirangkai ke mbali dalam pembuatan karakter. Seperti yang terlihat pada Gambar 2 dibawah ini

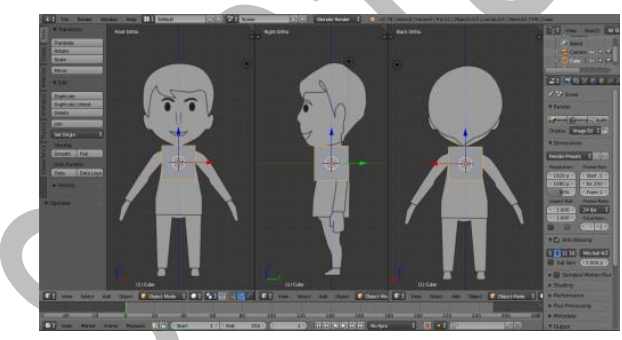

Gambar 2 Blueprint Karakter dengan Cube Object

Extrude memiliki fungsi ialah menambah atau memperluas vertex, edge, atau face yang sedang terseleksi. Penggunaan extrude ini terdapat pada beberapa proses pembuatan seperti pembuatan tangan, kaki, dan leher pada karakter 3D seperti pada Gambar 3 dibawah ini

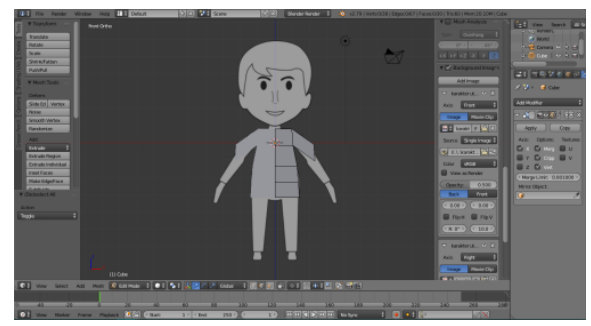

Gambar 3 Extrude Karakter

Loop cut and slide adalah fitur yang memiliki fungsi yang dapat membagi sebuah objek khususnya edge dan vertex menjadi beberapa bagian secara otomatis. Dalam pembuatan model karakter 3D ini digunakan untuk membentuk lekukan pada badan dan kepala pada objek. 


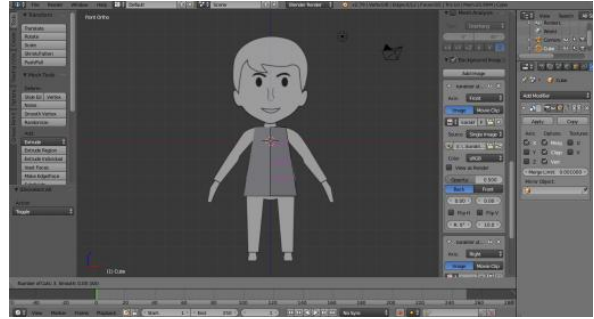

Gambar 4 Loop cut and slide

b. Texture Karakter, pemberian warna dan tekstur pada karakter model 3D in i dilakukan dengan menggunakan teknik UV mapping, pemberian texture dapat diatur ukuran dan posisi yang berbeda pada setiap sisi objek sesuai dengan yang dibutuhkan. Setelah $u v$ maping dilakukan maka akan menghasilkan warna karakter dengan hasil sebagai berikut

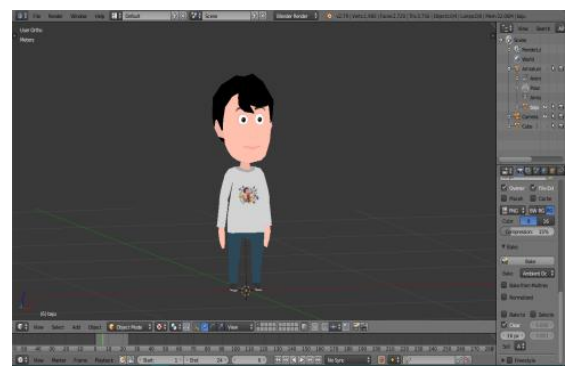

Gambar 5 Hasil Texturing

c. Rigging, rigging pada karakter 3D adalah tahapan pemberian tulang pada objek 3D tersebut agar objek menjadi lebih dinamis. Pada tahap ini menggunakan armature single bone. Penggunaan armature single bone ini memudahkan dalam pengaturan posisi tulang sesuai kebutuhan. Armature single bone ini akan di-extrude sesuai bentuk lekukan tubuh pada karakter 3D. Jika proses penggabungan bone dengan objek berhasil dilakukan maka secara otomatis karakter $3 \mathrm{D}$ tersebut dapat digerakan. Seperti yang terlihat pada Gambar 6 dibawah in $\mathrm{i}$

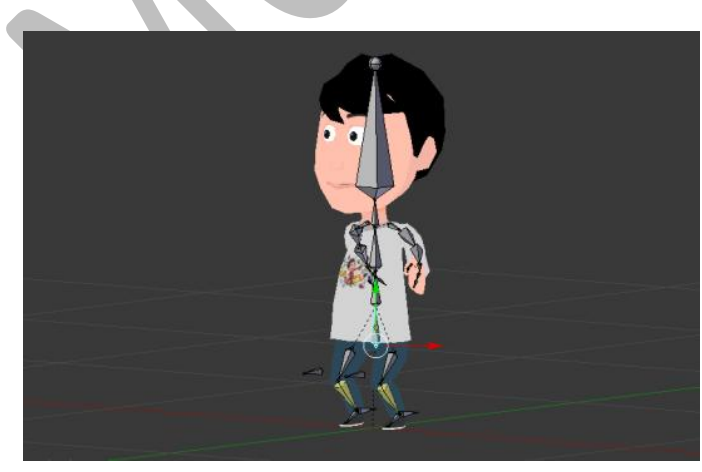

Gambar 6 Hasil Rigging

d. Animating, permainan "World War D" dibutuhkan pergerakan atau animasi pada model karakter 3D, diantaranya ialah idle, berlari, melompat, dan menyerang. Pembuatan animasi ini dilakukan dengan mengubah posisi dan rotasi yang ada pada controller karakter sehingga mendapatkan pose yang dibutuhkan. Perubahan posisi dan rotasi pada seluruh pergerakan karakter direkam dalam key frame pada timeline yang tersedia pada panel action editor mode. Dapat dilihat seperti Gambar 7 dibawah ini

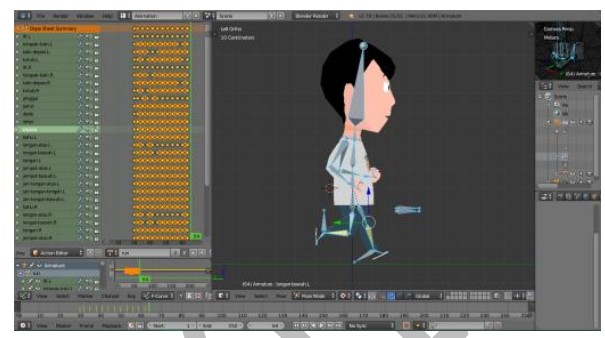

Gambar 7 Animating Karakter

5. Pengujian (Testing), pada tahap ini dilakukan pengujian alfa untuk menguji karakter 3D yang telah dibuat. Pengujian alfa ini dilaku kan secara internal oleh tim pembuat khususnya pembuat karakter (modeler) dengan melihat dan meneliti hasil karakter yang dibuat dengan yang sudah dirancangkan sebelumnya. Dan pengujian beta yang dilakukan dengan cara penyebaran kuisioner dan uji coba lapangan oleh calon pengguna. Pengujian pada mobile game "World War D" berbasis Android dilakukan setelah proses pembuatan selesai. Tahap pengujian merupakan tahap kelima setelah dilakukan assembly pada metode pengembangan Luther. Pengujian ini dilakukan terhadap hasil modeling, texturing, coloring dan animating pada aplikasi android.

a. Alpa Testing, Dari hasil pengujian yang dilakukan pada warna, tekstur dan animasi maka didapatkan hasil yang menunjukan bahwa ditemukan terdapat error system di dalam beberapa aspek penilaian namun dilakukannya kembali perbaikan yang menghasil hasil uji valid. Hasil akhir pengujian warna dan tekstur sudah sesuai dengan yang diinginkan. Serta animasi yang diuji sudah sesuai dengan gerakan asli manusia yang biasa dilakukan sehari-hari. Serta menerapkan 7 dari 12 prinsip dasar animasi, yaitu anticipation, straight ahead action and pose to pose, archs, secondary action, timing, solid drawing dan appeal. Serta squashstretch, staging, exaggeration, ease in and ease out, dan follow through and overlapping action tidak diterapkan pada animasi karakter karena yang dibuat merupakan jen is animasi sederhana.Dari hasil alpha testing yang telah dijabarkan di atas, dapat disimpulkan bahwa alpha testing pada seluruh komponen yang diuji menunjukan 
hasil yang valid. Sehingga alpha testing ini membuktikan bahwa karakter pada permainan "World War D" sudah cukup baik untuk dilanjutkan pada tahap beta testing

b. Beta Testing, berdasarkan hasil beta testing, responden menilai animasi sudah berjalan dengan baik seperti yang seharusnya. Responden juga menilai warna dan tekstur pada karakter 3D sudah cocok dengan tema game secara keseluruhan. Hal ini dibuktikan dengan rata-rata persentase sebesar $29,93 \%$ pada jawaban "sangat setuju" dan 56,01\% untuk jawaban "setuju" pada kuisioner.

6. Distribusi, tahap di mana hasil dari membuat dan menganimasikan karakter 3D pada permainan 'World War D' didistribusikan kepada programmer aplikasi permainan untuk selanjutnya digunakan dalam pembuatan aplikasi mobile game.

\section{KES IMPULAN}

Berdasarkan hasil pengerjaan skripsi yang berjudul "Modeling 3D dan Animating Pada Game Edukasi "World War D" Berbasis Android dapat disimpulkan bahwa

a. Pembuatan model 3D karakter pemain utama dan karakter bakteri sebanyak tiga objek (enemy) sebagai aset utama pada aplikasi permainan "World War D" sudah berhasil dibuat.

b. Pembuatan animasi pada model 3D karakter pada permainan "World War D" telah berhasil dibuat.

c. Berdas arkan hasil alpha testing, objek 3D pada karakter serta animasi yang dibuat memiliki error system ketika dimasukan kedalam game engine namun langsung dilakukan perbaikan.

d. Berdasarkan hasil beta testing, responden menilai animasi sudah berjalan dengan baik seperti yang seharusnya. Responden juga menilai warna dan tekstur pada karakter 3D sudah cocok dengan tema game secara keseluruhan. Hal ini dibuktikan dengan ratarata persentase sebesar $29,93 \%$ pada jawaban "sangat setuju" dan 56,01\% untuk jawaban "setuju" pada kuisioner.

\section{REFERENS I}

[1] Kementerian Kesehat an Republik Indonesia. (2017, Juli). Profil Kesehatan Indonesia. Diambil kembali dari Profil Kesehat an Indonesia 2016: http://www.kemkes.go.id

[2] Pracoyo, N. E. (2013). Hubungan Antara Pengetahuan dan Sikap Pengelola Vaksin dengan Skor Pengelolaan Vaksin di Daerah Kasus Difteri di Jawa Timur. Media Litbangkes, 102-109.

[3] Marianti, d. (2017). Penyakit Difteri. Diambil kembali dari Alodokter - Informasi Kesehatan Terlengkap dan Terpercaya: http://www.alodokter.com/difteri

[4] Rizky, M. (2017, Desember 12). Soal Wabah Difteri, DPR: Imunisasi Dasar Lengkap Tak Pernah sampai 100\%. Dipetik April 2, 2018, dari Okezone News: https://news.okezone.com/read/2017/12/12/337/1829362/ soal-wabah-difteri-dpr-imunisasi-dasar-len gkap-takpernah-sampai-100

[5] Fauzi, M., Cahyana, R., \& Tresnawati, D. (2013). Pembuatan Game Edukasi Pengenalan Karies Untuk Anak Usia 6-8 Tahun. Jumal Algoritma.

[6] Putra, A. R. (2017, Desember). Mempercantik Tampilan Game 2D Menjadi 3D De Kronik Van Diponegoro Menggunakan Teknik Mode 7. Jumal Teknik Elektro.

[7] Clemenson, G. D., \& Stark, C. E. (2015). Virtual Environmental Enrichment through Video Games Improves Hippocampal-Associated Memory. The Journal of Neuroscience.

[8] World Health Organization. (2015). Diphtheria - The Disease. Diambil kembali dari World Health Organization:

http://www.who.int/immunization/topics/diphtheria/en/in dex 1.html

[9] Baron, S. (1996). Medical Microbiology, 4th Edition. Texas: University of T exas Medical Branch.

[10] Ekawati, P. L. (2015, Februari). Pemanfaatan Teknologi Game Untuk Pemebelajaran Mengenal Ragam Budaya Indonesia Berbasis Android. Jumal Link, 22.

111] Technopedia. (2017). Mobile Games. Diambil kembali dari Technopedia: https://www.techopedia.com/definition/24261/mobilegames

[12] Anggraini, A. F., Erviana, N., Anggraini, S., \& Prasetya, D. D. (2016). Aplikasi Game Edukasi Petualangan Nusantara. Prosiding SENTIA, VIII, A168-A172.

[13] International Design School. (2016, November 25). Memahami Lebih Dalam Pengertian Animasi 3D. Diambil kembali dari International Design School: https://idseducation.com/articles/memahami-lebih-dalampengertian-animasi-3d/

[14] Slick, J. (2018, Maret 25). What Is 3D Modeling? Diambil kembali dari Lifewire: https://www.lifewire.com/what-is-3d-modeling-21 64

[15] Adeyanju. (2015). 3D-Computer Animation For A Yoruba NAtive Folktale. Inemational Journal of Computer Graphics \& Animation, 20-27.

[16] Bhatti, Z. (2017). Be-Educated: Multimedia Learning Through 3D Animation. Intemational Journal of Computer Science and Emerging Technologies, 13-22.

[17] International Design School. (2014, Juni 13). Apa Itu Animasi? Diambil kembali dari International Design School: https://idseducation .com/articles/apa-itu-animasi/ 